OPEN ACCESS

Edited by:

Katja Upadyaya,

University of Helsinki, Finland

Reviewed by:

Balwant Singh,

Partap College of Education, India

Sergi Fàbregues,

Open University of Catalonia, Spain

*Correspondence:

Jingping Zhang

jpzhang1965@csu.edu.cn

tThese authors have contributed equally to this work and share first authorship

Specialty section: This article was submitted to Gender, Sex and Sexualities,

a section of the journal

Frontiers in Psychology

Received: 24 February 2021

Accepted: 13 December 2021

Published: 14 January 2022

Citation:

Li Y, Zuo M, Peng Y, Zhang J, Chen $Y$, Tao $Y, Y e B$ and Zhang $J$ (2022) Gender Differences Influence Gender Equality Awareness, Self-Esteem, and Subjective Well-Being Among School-Age

Children in China.

Front. Psychol. 12:671785 doi: 10.3389/fpsyg.2021.671785

\section{Gender Differences Influence Gender Equality Awareness, Self-Esteem, and Subjective Well-Being Among School-Age Children in China}

\author{
Yifei $\mathrm{Li}^{1+}$, Man Zuo ${ }^{2 t}$, Yirong Peng ${ }^{3}$, Jie Zhang ${ }^{1}$, Yiping Chen ${ }^{1}$, Yingxiang Tao ${ }^{1}$, Biyun Ye ${ }^{1}$ \\ and Jingping Zhang ${ }^{1 *}$
}

'Nursing Psychology Research Center, Xiangya School of Nursing, Central South University, Changsha, China, ${ }^{2}$ Heyuan
People's Hospital, Heyuan, China, ${ }^{3}$ Guijing Primary School, Changsha, China

The objective of this study was to investigate and analyze the status and influential factors of gender equality awareness, self-esteem, and subjective well-being in schoolage boys and girls. The results can help schools and teachers provide more effective gender equality and mental health education. In the study, 284 valid questionnaires were collected from a total of 323 school-age boys and girls in the Hunan Province, China (effective response rate of $87.93 \%$ ). The questionnaire covered gender equality awareness, self-esteem, and subjective well-being, with the influencing factors analyzed through multiple linear regression. There was a significant correlation among children's gender equality awareness in all areas examined (family, occupation, and school), with both boys and girls having the lowest awareness of gender equality in occupational fields. The children's self-esteem and subjective well-being were significantly correlated as well. Gender equality awareness, self-esteem, and subjective well-being among boys and girls reflected different influential factors. Androgynous traits (neither feminine nor masculine) were conducive to the development of gender equality awareness and self-esteem among the children. Therefore, schools and teachers need to provide gender equality and mental health education according to the specific psychological characteristics of each boy and girl.

\section{Keywords: school-age children, gender, gender equality awareness, self-esteem, subjective well-being}

\section{INTRODUCTION}

Many studies have found that there are significant differences in gender equality awareness and mental health among different genders (Tennant et al., 2007; Tang et al., 2011). Men usually have lower gender equality awareness (Tang et al., 2011), whereas women usually have lower mental health (Tennant et al., 2007). Lower gender equality perceptions and lower mental health not only create psychological problems, such as anxiety and depression (Derdikman-Eiron et al., 2011; Holter, 2014), but also can endanger one's physical health (Clarke et al., 2011; Holter, 2014) and increase the risk of death (Happell et al., 2017; Kolip et al., 2019). Studies have found that a high sense of gender equality can promote both men's and women's physical, mental, and sexual health 
(Bates et al., 2009; Syed, 2017); the higher the national gender equality index and personal mental health level, the longer the life expectancy of men and women (Kolip and Lange, 2018; Zaninotto and Steptoe, 2019; Gadoth and Heymann, 2020).

Common measures of individual mental health include self-esteem and subjective well-being (Derdikman-Eiron et al., 2011; Joshanloo and Daemi, 2015). As an important part of a healthy personality, self-esteem can affect both positive and negative psychological states of an individual (NartovaBochaver et al., 2019). Moreover, it is regarded as an important measure of mental health (Jin, 2014). Subjective well-being is a comprehensive evaluation of personal life according to subjective standards, which combine emotional experiences with life satisfaction (Wang, 2021), and is significantly correlated with 24 positive personality traits such as love and gratitude (Zhou and Liu, 2011). This is the most common positive psychological experience related to mental health (Derdikman-Eiron et al., 2011). High self-esteem and subjective well-being are associated with higher mental health (Derdikman-Eiron et al., 2011). An egalitarian perception of gender awareness leads to a higher sense of self-esteem and subjective well-being for both men and women (Schmitt et al., 2017). Men generally have higher self-esteem and subjective well-being than women, especially in areas with high gender equality (Derdikman-Eiron et al., 2011; Schmitt et al., 2017).

Most adult gender equality awareness and psychological problems stem from childhood, especially at school age (Rutter et al., 2006; Solbes-Canales et al., 2020). School age refers to the period of development from primary school to adolescence, usually between 6 and 12 years of age (Cui, 2013). At this stage, children are in a critical development period of individual gender equality awareness, self-esteem, and subjective wellbeing. Solbes-Canales et al. (2020) found gender stereotypes in children aged 4-9 years old and significant differences in different gender groups. Trautner et al. (2005) found that individual gender stereotypes appeared at the age of five, reached a peak of rigidity at 7 or 8 years of age, and then gradually gained flexibility as children's gender cognition and understanding deepened. Zhang's (2004) research on children aged 3-9 years old found that $4-5$ years old and 7-8 years old were two key transitional periods for children's self-esteem development. Casas and González-Carrasco's (2019) analysis of children aged 714 in 15 countries found that in most countries, 10 years old was the transitional period for children's subjective well-being. Moreover, significant differences in self-esteem and subjective well-being among school-age children of different genders have been found (Zhang, 2004, 2012; Savoye et al., 2015). Studies point out that higher gender equality, self-esteem, and subjective well-being can improve the mental health and life satisfaction of school-age children (Zhang, 2012; Looze et al., 2018). Overall, school age is a critical development period for gender equality awareness, self-esteem, and the subjective well-being among children. Positive gender equality awareness, self-esteem, and subjective well-being can have a positive impact on school-age children, and there are significant differences in gender equality awareness, self-esteem, and subjective well-being among children of different genders.
In general, biological and sociological theories are used to explain the psychological and behavioral differences among children of different genders (Chaplin and Aldao, 2013; Chen, 2016). According to biological theories, gender differences in psychology and behavior are caused by congenital factors, such as sex hormones, chromosomes, genes, and heredity (Feingold, 1994; Chaplin and Aldao, 2013). According to sociological theories, children's gender equality awareness and role development are formed through social learning and cognition (Chaplin and Aldao, 2013; Chen, 2016). Children of different genders will have different gender role responses in different or similar groups (Rose and Rudolph, 2006; Chen, 2016). Gender roles refer to the gender characteristics that a society assigns to men and women (Bem, 1981). For example, men tend to be seen as independent, aggressive, and ambitious, whereas women are seen as affectionate, gentle, and compassionate (Bem, 1974). "Masculinity" refers to individuals who have highly masculine characteristics and "femininity" refers to individuals who have highly feminine characteristics; individuals with both highly masculine and highly feminine traits are considered "androgynous." Those who have both low masculine and low feminine characteristics are considered "undifferentiated" (Bem, 1974). Studies have shown that androgynous profiles predict positive outcomes, such as greater self-esteem and mental health (Arcand et al., 2020).

However, with further investigation in many studies, more and more scholars have found that gender differences in individual psychological and behavioral responses are influenced by a wide variety of factors (Brody, 1999; Fang, 2010). Consequently, Wood and Eagly (2002) proposed a new concept called the biosocial model. This model posits that the differences in gender equality awareness and psychological behavior responses between men and women are caused by social, cultural, and environmental interventions along with biological factors such as genes and hormones, mainly influenced by congenital factors, critical development periods, and parenting (Chen, 2016). Therefore, under the premise that biological factors cannot be changed, understanding the key development periods for children's gender equality awareness and psychology, targeted, reasonable education, and guidance for children of different genders have become a research focus.

According to several scholars, the transitional periods of children's gender equality awareness, self-esteem, and subjective well-being appear at school age (Zhang, 2004; Trautner et al., 2005; Casas and González-Carrasco, 2019). Moreover, some have found that school and teacher support are more conducive than family and other social support in enhancing children's gender equality, self-esteem, and subjective well-being (Chu et al., 2010; Weber et al., 2010; Chen, 2016). Hence, a positive educational environment can also effectively promote children's physical and mental health, along with their academic development (Atkins et al., 2017). Therefore, during primary education, schools and teachers should help children establish gender equality awareness, self-esteem, subjective well-being, and other positive psychological states through education and interventions, which will be critical for their future physical and mental health and also their academic success. 
Compared with the United States, Sweden, Taiwan, and other regions (Li, 2007; Liu, 2015; Brener and Demissie, 2018; OkenwaEmgwa and von Strauss, 2018), gender equality and mental health education on the Chinese mainland started late and is still in an exploratory stage. Relevant courses and activities have been conducted only in some regions and schools, with short follow-up. Moreover, there are few studies on gender equality awareness, self-esteem, and subjective well-being among Chinese school-age boys and girls. This study aims to fill this gap by providing theoretical and educational guidance for education and intervention in schools through the investigation and analysis of gender differences in school-age children's gender equality awareness, self-esteem, and subjective well-being in China. Our objective is to help teachers and other practitioners to improve gender equality awareness, self-esteem, and subjective well-being among school-age children.

\section{MATERIALS AND METHODS}

\section{Design and Sample}

Participants were recruited from two primary schools in Hunan Province, China, through convenience sampling from June 15, 2020 to June 19, 2020. The screening criteria were as follows: (1) students had to be in grades first through sixth and were willing to voluntarily participate in the study; (2) had their parents' consent; and (3) had not participated in other studies on gender equality and mental health of children.

The principal of the research group contacted the cooperative schools in advance of the study. After unified training, a researcher and a class teacher introduced the study's purpose, content, and questionnaire terms to the children. After obtaining consent from the children and parents, the questionnaire was distributed and collected on-site. The children were free to ask questions, and members of the research team explained questions that the children did not understand.

Power analysis using the GPower software showed that a minimum of 210 participants were required to achieve a significant outcome (Effect size $d: 0.5$, $\alpha$ error prob.: 0.05 , Power: $0.95)$. A total of 323 questionnaires were returned and 284 were valid in this study, with a recovery rate of $87.93 \%$.

\section{Measurements}

The questionnaire consisted of the following five sections.

\section{Demographic Characteristics}

The demographic data section collected the following: gender, age, grade, number of same-sex friends, number of opposite-sex friends, whether the child had siblings, whether the child had been left-behind, parental marital status, frequency of parental quarrels, children's gender satisfaction, and attitudes toward gender-neutral dressing for boys and girls.

\section{Gender Equality Awareness Questionnaire}

The gender equality awareness section was developed by Tang et al. (2011). The questions involved attitudes toward gender equality in family fields (e.g., who do you think should do the cooking?), school fields (e.g., who do you think the teacher should give more chances to act as a monitor?), and occupational fields (e.g., who do you think is more suitable to be a kindergarten teacher?). Each area contained 10 items, for a total of 30 items. For scoring, option B (same for men and women) was coded as 1 , and options A (more suitable for men) and C (more suitable for women) were both coded as 0 . The higher the total score, the stronger the consciousness of gender equality. Cronbach's alpha was 0.92 here.

\section{Bem Sex Role Inventory}

The Bem Sex Role Inventory (BSRI) was designed by Bem (1974) and translated by $\mathrm{Lu}$ and $\mathrm{Su}$ (2003) to measure gender role orientation. It was scored on a 7-point Likert-type scale where 1 represented "never true" and 7 "always true." It contained three subscales: a 14-item masculinity scale (e.g., ambitious and aggressive), a 12-item femininity scale (e.g., gentle and affectionate), and a 20 -item gender-neutral scale (e.g., helpful and happy). The total score of the masculinity scale was divided by 14 , and the total score of the femininity scale was divided by 12 . If the scores of both masculine and feminine items were greater than four, the measurement result was considered androgynous. If only the masculinity scale was higher than four, the result was masculine; if only the femininity scale score was higher than four, the result was feminine; if both masculinity and femininity scales' scores were less than four, the result was undifferentiated. The BSRI had an internal consistency and test-retest reliability of around 0.80 ( $\mathrm{Lu}$ and $\mathrm{Su}, 2003$ ). Cronbach's alpha was 0.92 here.

\section{Rosenberg Self-Esteem Scale}

The Rosenberg Self-esteem Scale (RSES) was designed by Rosenberg (Lee, 1969) and translated by Yu and Ji (1993). It is the most widely used questionnaire to assess self-esteem. The scale includes 10 items, scored on a 4-point Likert-type scale ranging from 1 (strongly disagree) to 4 (strongly agree). The overall selfesteem factor was calculated by a sum score ranging from 10 to 40; higher scores indicated higher self-esteem. Cronbach's alpha was 0.78 for the Chinese version (Yu and Ji, 1993) and 0.62 here.

\section{Subjective Well-Being}

The subjective well-being measurement, designed by Andrews and Withey (Lorish and Maisiak, 1986) and translated by Zhang (2010), was a simplified face scale. This brief and pictorial mood scale used a sequence of seven faces that did not require reading literacy. Cronbach's alpha was 0.7 for the overall scale.

\section{Ethical Considerations}

The study was reviewed by the Institutional Review Board in the researchers' university (ethical grant number: E201947). Prior to the survey, the researchers informed subjects of the purpose, method, and considerations of the study, and they could quit at any time during the filling process. Researchers issued the anonymous questionnaire to all eligible children after acquiring written informed consent. A quiet and private meeting room was provided for participants to complete the questionnaire. Questionnaires were retrieved immediately, and only 
the researchers had access to the data. The cover page of the questionnaire contained contact information of psychological consultation.

\section{Data Analysis}

SPSS software (version 21.0) was used for statistical analysis. Categorical data were expressed as frequencies and percentages. Measurement data were expressed as mean \pm SD. An independent sample $t$-test and one-way ANOVA were used to analyze the demographic data of gender equality awareness, selfesteem, and subjective well-being. The significant variables in the univariate analysis were included in the multiple linear regression equation. Gender equality awareness, self-esteem, and subjective well-being of school-age children were analyzed through multiple factors. Incorporating all possible variables, we used multiple stepwise regression to analyze the factors influencing gender equality awareness, self-esteem, and the subjective well-being of children of different genders. Statistical significance was set at $p<0.05$.

\section{RESULTS}

\section{Participant Demographics}

Among the 284 participants, 133 were boys and 151 were girls, with a mean age of 9.49 ( $\mathrm{SD}=1.716$, range $=6-13)$ years old. Most participants had siblings (76.06\%), had not been left-behind (66.90\%), had very good parental feelings (55.99\%), had parents who did not quarrel $(46.48 \%)$ or quarreled little $(46.83 \%)$, had more than three same-sex (62.68\%) and opposite-sex friends (36.62\%), were satisfied with their gender (49.65\%), and were categorized as androgynous (59.51\%). As for the attitudes of the children toward gender-neutral dress for boys and girls, 44.02\% did not like gender-neutral dressing among boys, $44.01 \%$ did not like gender-neutral dressing among girls, and $44.72 \%$ did not care about gender-neutral dressing among girls (see Table $\mathbf{1}$ ).

\section{Gender Equality Awareness, Self-Esteem, and Subjective Well-Being of School-Age Children}

Table 2 shows the descriptive analysis of gender equality awareness, self-esteem, and subjective well-being of schoolage children. The children's average score for gender equality awareness was $17.29 \pm 8.04$, gender equality awareness of family fields was $6.32 \pm 2.73$, gender equality awareness of occupational fields was $5.14 \pm 3.20$, gender equality awareness of school fields was $5.84 \pm 3.21$, self-esteem was $27.74 \pm 4.73$; and subjective well-being was $2.31 \pm 1.45$. We correlated the scores of gender equality awareness for family, school, and occupational fields, and the self-esteem and subjective well-being scores (see Table 3).

Figure 1 shows the average score of gender equality awareness among children of different genders in all fields. Both boys and girls scored lower in occupational fields than in family and school fields. Figure 2 shows that the overall gender equality awareness of boys and girls increased with each grade.

\section{Analysis on the Influential Factors of School-Age Children's Gender Equality Awareness}

Table 4 shows that gender, grade, gender role, and attitude toward gender-neutral dressing for boys were the main factors influencing gender equality awareness among all children. Table 5 shows that the main factors influencing gender equality awareness among the boys were grade, whether they were an only child, gender satisfaction, and their attitude toward genderneutral dressing for boys. The main factors influencing gender equality awareness among the girls were grade, whether they were an only child and whether they were left-behind, the number of opposite-sex friends, and gender roles.

\section{Analysis on the Influential Factors of School-Age Children's Self-Esteem}

Table 6 shows that gender role, parental feelings, and number of same-sex friends were the main factors influencing self-esteem. Table 7 shows that parental feelings were the main factor that affect the boys' self-esteem, whereas gender role was the main factor that affect the girls' self-esteem.

\section{Analysis on the Influential Factors of School-Age Children's Subjective Well-Being}

In Tables 8, 9, we show that subjective well-being was affected mainly by the extent of parental quarrels, which was more harmful for girls.

\section{DISCUSSION}

In our study, the average scores for the children were as follows: gender equality awareness was $17.29 \pm 8.04$; self-esteem was $27.74 \pm 4.73$; and subjective well-being was $2.31 \pm 1.45$. Gender equality awareness across family, occupation, and school fields was significantly correlated. There was a significant correlation between self-esteem and subjective well-being as well. However, there was no correlation between gender equality awareness and self-esteem and subjective well-being. This may be due to the fact that our sample was small compared with previous studies that utilized large samples across borders or across regions (Campbell et al., 2021). We conducted a survey only in Hunan Province, China, and all the children were from the same gender, sociocultural environment.

\section{Analysis on the Status and Influential Factors of School-Age Children's Gender Equality Awareness}

In our study, as stated above, school-age children's family, occupation, and school gender equality awareness scores were significantly correlated. Girls' gender equality awareness was slightly higher than that of the boys' overall gender equality awareness and in the various fields. However, both male and female students had the lowest gender equality awareness of 
TABLE 1 | Relationships among socio-demographic characteristics and variable scores $(N=284)$.

\begin{tabular}{|c|c|c|c|c|c|c|c|c|c|c|}
\hline Variables & $N(\%)$ & $\begin{array}{l}\text { Gender } \\
\text { equality } \\
\text { awareness }\end{array}$ & $t / F$ & $p$ & Self-esteem & $t / F$ & $p$ & $\begin{array}{l}\text { Subjective } \\
\text { well-being }\end{array}$ & $t / F$ & $p$ \\
\hline \multicolumn{11}{|l|}{ Gender } \\
\hline Male & $133(46.83)$ & $15.86 \pm 8.31^{\star}$ & \multirow{2}{*}{-2.843} & \multirow{2}{*}{0.005} & $27.95 \pm 5.01$ & \multirow{2}{*}{0.720} & \multirow{2}{*}{0.472} & $2.19 \pm 1.31$ & \multirow{2}{*}{-1.311} & \multirow{2}{*}{0.191} \\
\hline Female & $151(53.17)$ & $18.55 \pm 7.60$ & & & $27.55 \pm 4.47$ & & & $2.41 \pm 1.56$ & & \\
\hline \multicolumn{11}{|l|}{ Grade } \\
\hline 1 & $17(5.98)$ & $8.82 \pm 7.40^{\star \star}$ & \multirow{6}{*}{16.828} & \multirow{6}{*}{0.000} & $25.41 \pm 4.71^{\star}$ & \multirow{6}{*}{2.304} & \multirow{6}{*}{0.045} & $2.18 \pm 0.69$ & \multirow{6}{*}{0.338} & \multirow{6}{*}{0.890} \\
\hline 2 & $69(24.30)$ & $14.78 \pm 7.14$ & & & $26.99 \pm 4.00$ & & & $2.15 \pm 1.53$ & & \\
\hline 3 & 55 (19.37) & $14.55 \pm 5.71$ & & & $28.58 \pm 3.52$ & & & $2.28 \pm 1.51$ & & \\
\hline 4 & 37 (13.03) & $17.86 \pm 8.36$ & & & $27.16 \pm 5.28$ & & & $2.41 \pm 1.55$ & & \\
\hline 5 & $48(16.90)$ & $19.17 \pm 7.37$ & & & $27.81 \pm 5.15$ & & & $2.36 \pm 1.29$ & & \\
\hline 6 & 58 (20.42) & $23.00 \pm 7.10$ & & & $28.83 \pm 5.47$ & & & $2.45 \pm 1.56$ & & \\
\hline \multicolumn{11}{|l|}{ The only child } \\
\hline Yes & 68 (23.94) & $17.18 \pm 8.52$ & \multirow{2}{*}{-0.136} & \multirow{2}{*}{0.892} & $28.16 \pm 5.18$ & 884 & 388 & $2.36 \pm 1.47$ & 0338 & 0736 \\
\hline No & $216(76.06)$ & $17.33 \pm 7.90$ & & & $27.61 \pm 4.58$ & 0.044 & 0.000 & $2.29 \pm 1.45$ & 0.000 & 0.150 \\
\hline The left-behind & & & & & & & & & & \\
\hline Yes & 94 (33.10) & $16.57 \pm 7.77$ & 1058 & م201 & $27.13 \pm 4.57$ & 1538 & 0125 & $2.29 \pm 1.36$ & 0160 & 873 \\
\hline No & $190(66.90)$ & $17.65 \pm 8.17$ & & 0.291 & $28.04 \pm 4.78$ & -1.538 & 0.120 & $2.317 \pm 1.498$ & 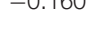 & 0.813 \\
\hline Parents' feeling & & & & & & & & & & \\
\hline Good feelings & 159 (55.99) & $17.94 \pm 8.14$ & & & $28.40 \pm 4.64^{\star}$ & & & $2.03 \pm 1.29^{\star}$ & & \\
\hline Average & 87 (30.63) & $16.84 \pm 7.29$ & 213 & 0.97 & $27.14 \pm 4.44$ & 2.98 & 032 & $2.79 \pm 1.57$ & 5.447 & 1 \\
\hline Bad feelings & $14(4.93)$ & $13.14 \pm 7.29$ & & & $25.43 \pm 5.39$ & & & $2.26 \pm 1.31$ & & \\
\hline Divorce & $24(8.45)$ & $15.43 \pm 8.31$ & & & $26.74 \pm 5.03$ & & & $2.62 \pm 1.67$ & & \\
\hline Parental quarre & & & & & & & & & & \\
\hline Never & $132(46.48)$ & $17.95 \pm 8.02$ & & & $28.17 \pm 7.73$ & & & $2.04 \pm 1.29^{\star \star}$ & & \\
\hline Few & 133 (46.83) & $16.19 \pm 7.63$ & 1.764 & 0.173 & $27.56 \pm 4.54$ & 2.089 & 0.126 & $2.40 \pm 1.42$ & 11.459 & 0.000 \\
\hline Many & 19 (6.69) & $18.21 \pm 8.75$ & & & $25.89 \pm 5.374$ & & & $3.66 \pm 1.89$ & & \\
\hline Number of sam & & & & & & & & & & \\
\hline 0 & $18(6.34)$ & $14.53 \pm 8.87$ & & & $27.29 \pm 3.84^{*}$ & & & $2.095 \pm 1.30^{*}$ & & \\
\hline 1 & 35 (12.32) & $16.35 \pm 7.89$ & 1.138 & 0.334 & $25.38 \pm 5.36$ & 4.836 & 0.003 & $3.04 \pm 1.67$ & 3.276 & 0.022 \\
\hline $2-3$ & $53(18.66)$ & $16.31 \pm 7.28$ & 1.130 & 0.334 & $26.94 \pm 3.40$ & 4.000 & 0.003 & $2.26 \pm 1.41$ & 0.270 & 0.022 \\
\hline$>3$ & $178(62.68)$ & $17.65 \pm 8.03$ & & & $28.44 \pm 4.82$ & & & $2.22 \pm 1.40$ & & \\
\hline Number of opp & & & & & & & & & & \\
\hline 0 & $77(27.11)$ & $16.82 \pm 8.31$ & & & $27.72 \pm 4.99$ & & & $2.52 \pm 1.50$ & & \\
\hline 1 & 54 (19.02) & $16.50 \pm 8.76$ & ० ८०२ & 0.94 & $26.65 \pm 3.50$ & 2358 & 072 & $2.561 \pm 1.54$ & 1818 & 0144 \\
\hline $2-3$ & $49(17.25)$ & $16.04 \pm 7.55$ & 0.002 & 0.494 & $27.02 \pm 5.93$ & 2.350 & 0.012 & $2.22 \pm 1.53$ & 1.010 & 0.144 \\
\hline$>3$ & $104(36.62)$ & $17.97 \pm 7.40$ & & & $28.57 \pm 4.27$ & & & $2.32 \pm 1.45$ & & \\
\hline Gender satisfac & & & & & & & & & & \\
\hline Dissatisfied & $36(12.68)$ & $14.50 \pm 6.79^{\star *}$ & & & $26.33 \pm 4.81$ & & & $1.99 \pm 1.44$ & & \\
\hline Indifferent & $107(37.67)$ & $19.93 \pm 8.28$ & 10.421 & 0.000 & $28.04 \pm 27.74$ & 1.873 & 0.156 & $2.19 \pm 1.48$ & 2.195 & 0.113 \\
\hline Satisfied & $141(49.65)$ & $16.00 \pm 7.64$ & & & $27.87 \pm 4.19$ & & & $2.48 \pm 1.42$ & & \\
\hline Boy gender-neu & & & & & & & & & & \\
\hline Dislike & $125(44.02)$ & $15.01 \pm 7.65^{\star *}$ & & & $27.90 \pm 4.29$ & & & $2.26 \pm 1.49$ & & \\
\hline Indifference & $82(28.87)$ & $19.96 \pm 7.84$ & 10.701 & 0.000 & $28.09 \pm 4.66$ & 0.991 & 0.372 & $2.52 \pm 1.36$ & 1.425 & 0.242 \\
\hline Like & $77(27.11)$ & $18.16 \pm 7.92$ & & & $27.10 \pm 5.43$ & & & $2.16 \pm 1.48$ & & \\
\hline Girl gender-neu & & & & & & & & & & \\
\hline Dislike & $125(44.01)$ & $16.40 \pm 7.72$ & & & $27.81 \pm 4.57$ & & & $2.39 \pm 1.48$ & & \\
\hline Indifference & $127(44.72)$ & $18.01 \pm 8.28$ & 1.179 & 0.309 & $27.74 \pm 4.53$ & 0.483 & 0.618 & $2.29 \pm 1.42$ & 1.768 & 0.173 \\
\hline Like & $32(11.27)$ & $17.17 \pm 7.71$ & & & $28.63 \pm 4.61$ & & & $1.84 \pm 1.14$ & & \\
\hline Sex role & & & & & & & & & & \\
\hline Undifferentiated & $45(15.85)$ & $14.58 \pm 7.68^{\star \star}$ & & & $26.02 \pm 4.65^{\star}$ & & & $2.21 \pm 1.42$ & & \\
\hline Masculinity & $26(9.15)$ & $14.54 \pm 7.65$ & 6836 & חח९ח & $27.77 \pm 4.46$ & 3 & & $2.58 \pm 1.70$ & & \\
\hline Femininity & $44(15.49)$ & $15.02 \pm 7.33$ & 0.836 & 0.000 & $27.11 \pm 5.45$ & 3.270 & 0.022 & $2.77 \pm 1.30$ & 2.361 & .071 \\
\hline Androgynous & $169(59.51)$ & $19.03 \pm 7.97$ & & & $28.36 \pm 4.49$ & & & $2.17 \pm 1.44$ & & \\
\hline
\end{tabular}

${ }^{* *} p=0.00,{ }^{*} p<0.05$, these scores were significantly higher or lower than those for other groups within the socio-demographic characteristics. 
TABLE 2 | Descriptive statistics of the measured variables $(N=284)$.

\begin{tabular}{lrccc}
\hline Variables & \multicolumn{1}{l}{ Mean } & SD & Median & Range \\
\hline Gender equality awareness & 17.29 & 8.04 & 17 & $0-30$ \\
Family fields & 6.32 & 2.73 & 6 & $0-10$ \\
Occupational fields & 5.14 & 3.20 & 5 & $0-10$ \\
School fields & 5.84 & 3.21 & 6 & $0-10$ \\
Self-esteem & 27.74 & 4.73 & 27 & $10-40$ \\
Subjective well-being & 2.31 & 1.45 & 2 & $1-7$ \\
\hline
\end{tabular}

the occupational field, whereas gender equality awareness was relatively high for family and school fields. This is consistent with the results of Tang et al. (2011). Moreover, this may relate to sex segregation in China's occupational environment. Previous studies have found (e.g., Li, 2016) that compared with developed countries and other developing countries, China's sex segregation is more significant. In China, $87.9 \%$ of professional women are engaged in low-grade, non-technical occupations, such as agriculture, forestry, service, and production, with the proportion of women in high-level occupations relatively low (Li, 2016). Both men and women in China are challenged by occupational gender stereotypes (Sun, 2010). This detrimental environment may have a negative impact on children's occupational gender equality awareness and also their future employment choices. Therefore, schools and teachers should strive to cultivate gender equality awareness in children and eliminate gender stereotypes in classroom education and extracurricular activities. Specifically in terms of occupational fields, teachers should emphasize that occupational choices should be made based on personal interest and practical ability, but not on gender.

We found that gender, grade, gender role, and attitude toward gender-neutral dressing for boys were the main factors that influence gender equality awareness. Among that for girls, the oldest, those having androgynous traits, and those indifferent to gender-neutral dressing for boys had higher awareness of gender equality, consistent with previous results (Tang et al., 2011; Li, 2019). Except for the third grade, gender equality awareness among both boys and girls improved with each grade. This may relate to the fact that children in the third grade are generally 7-8 years old. Previous studies (e.g., Trautner et al., 2005) have shown that in the development of children's gender equality awareness, children aged seven to eight are at the peak of gender stereotyping due to factors such as enhanced self-awareness and inadequate understanding of gender cognition. Subsequently, as children continue to learn and grow, their knowledge of gender expands and they are likely to exhibit more gender equality awareness (Trautner et al., 2005). Therefore, third-grade teachers need to pay special attention to cultivating the concept of gender equality, changing children's gender stereotypes through gender equality themed classes and storytelling. At the same time, teachers of all grades should encourage children's mixedgender communication through sports and team assignments to cultivate children's androgynous traits and educate children to respect their peers. In so doing, they can avoid prejudicing gender-neutral behavior and the appearance of boys and girls.

In our analysis, we found that girls falling under the androgynous category had higher gender equality awareness, whereas those in lower grades, who had siblings, had been leftbehind, and had fewer opposite-sex friends, had lower gender equality awareness. For gender equality awareness among boys, those in a lower grade, who were only children, and unsatisfied with boys' gender-neutral dressing had lower awareness. The different factors that affect gender equality awareness between male and female pupils, especially the "only child" difference, may relate to biological differences and the male-dominated social environment (Jiang et al., 2016; Polderman et al., 2018).

Most Chinese families have a preference for sons (Liao and Zhang, 2020). According to the Global Gender Gap Report 2018, China's sex ratio at birth ranks second to last among 149 countries (Wang et al., 2020). A survey of pregnant women in China by Loo et al. (2009) found that most pregnant women are more likely to believe they are pregnant with a boy. In Liao and Lian's (2020) study of mental health during China's only child and then more than one child policy between 1995 and 2017, they found that boys and only children generally had better mental health and positive development due to greater family care. As a result, boys, especially those with siblings, received more preference and family support than girls did. Thus, as the preferred child in the family, male children with siblings not only had a higher level of mental health than female children with siblings, but also were more intuitive about the existence of gender inequality than boys who were only children. The positive psychology of bearing witness to one's sister suffering from unequal treatment may produce a positive sense of gender equality among these boys. Female children with

TABLE 3 | Correlations among the measured variables $(N=284)$.

\begin{tabular}{|c|c|c|c|c|c|c|}
\hline & $\begin{array}{c}\text { Gender } \\
\text { equality } \\
\text { awareness }\end{array}$ & Family fields & $\begin{array}{c}\text { Occupational } \\
\text { fields }\end{array}$ & $\begin{array}{l}\text { School } \\
\text { fields }\end{array}$ & Self-esteem & $\begin{array}{l}\text { Subjective } \\
\text { well-being }\end{array}$ \\
\hline Gender equality awareness & 1 & & & & & \\
\hline Family fields & $0.851^{\star \star}$ & 1 & & & & \\
\hline Occupational fields & $0.905^{\star \star}$ & $0.683^{\star \star}$ & 1 & & & \\
\hline School fields & $0.878^{\star \star}$ & $0.601^{\star \star}$ & $0.689^{\star \star}$ & 1 & & \\
\hline Self-esteem & 0.083 & 0.102 & 0.026 & 0.094 & 1 & \\
\hline Subjective well-being & 0.036 & 0.017 & 0.019 & 0.058 & $-0.185^{\star \star}$ & 1 \\
\hline
\end{tabular}

${ }^{* *} p=0.00$. 


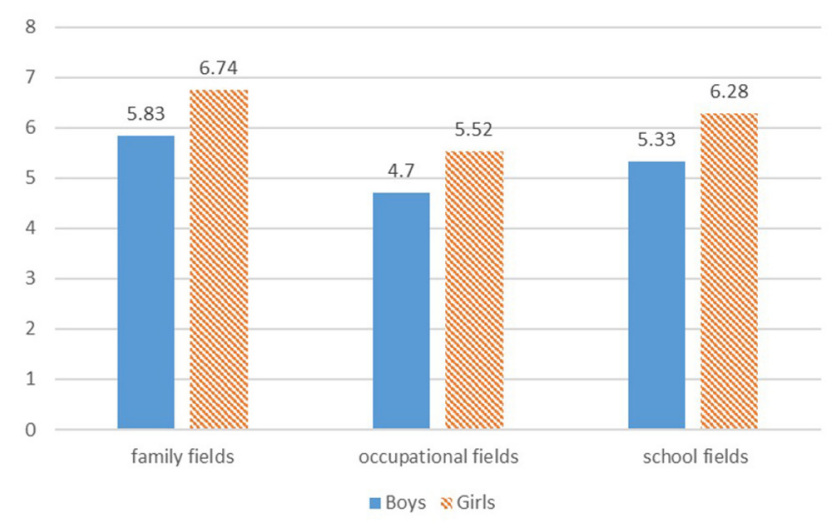

FIGURE 1 | Gender differences of gender equality awareness in all fields with school-age children.

siblings may be influenced by an unequal family atmosphere since childhood, propagating gender inequality. Moreover, they may be too accustomed to some inequalities to fight back. The low gender equality awareness of only children who are boys may relate to an unintuitive perception of the harm brought to others by gender inequality. Females who are only children and who have received all the support from their family may pursue gender equality due to the psychological gap that they face in gender inequality outside the family. Therefore, schools and teachers should focus on observing gender inequality awareness among school-age boys who are only children and girls who have siblings to help them establish gender equality concepts. Teachers should communicate with families with multiple children through family visits, explaining the importance of gender equality to the parents and other family members, guiding them to treat their sons and daughters equally.

In addition, schools and teachers should encourage school-age boys to respect male gender-neutral behaviors and appearance and improve their gender satisfaction. For school-age girls, especially girls who were left-behind, they may have negative gender equality awareness due to the absence of parents during

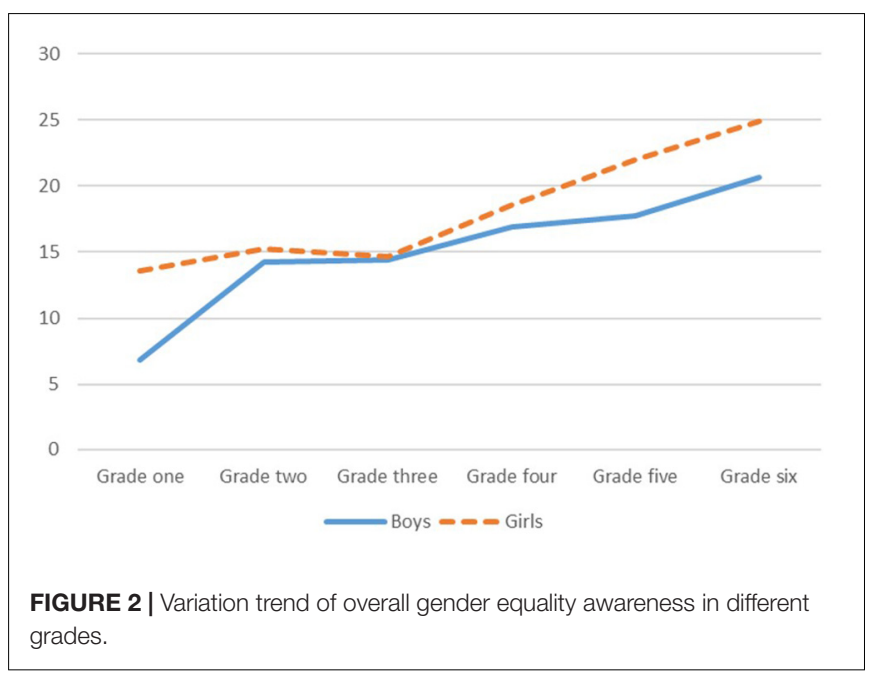

their growth (Wang, 2015). Therefore, teachers should give girls who were left-behind more care and teaching, increasing the contact between boys and girls by developing team games and other methods, cultivating children's androgynous roles, helping them make friends with the opposite sex, respecting different genders, and striving to cultivate a more positive awareness of gender equality among the children.

\section{Analysis on the Status and Influential Factors of School-Age Children's Self-Esteem and Subjective Well-Being}

In our study, children scored well in terms of self-esteem and subjective well-being; these scores were also correlated; the higher their self-esteem, the higher their subjective wellbeing, which is consistent with the results of previous studies (Wang, 2013). Those categorized as androgynous children had higher self-esteem, which is also consistent with previous studies (Juster et al., 2016). This may be because these children possess both male and female gender traits, have better psychological adaptability and adjustment ability, and are, therefore, more likely to develop positive self-esteem (Lo et al., 2019). School-age

TABLE 4 | Multiple linear regression analysis of the study variables on gender equality awareness.

\begin{tabular}{lccccc}
\hline $\begin{array}{l}\text { Dependent } \\
\text { variable }\end{array}$ & Independent variables & $\boldsymbol{B}$ & Beta & $\boldsymbol{t}$ & $\boldsymbol{p}$ \\
\hline $\begin{array}{l}\text { Gender equality } \\
\text { awareness }\end{array}$ & (Constant) & 1.580 & & 0.882 & 0.378 \\
& Gender & 2.204 & 0.137 & 2.692 & 0.008 \\
& Grade & 2.010 & 0.405 & 7.711 & 0.000 \\
& $\begin{array}{c}\text { Gender role } \\
\text { Attitudes toward boys' } \\
\text { gender-neutral dressing }\end{array}$ & 1.411 & 0.148 & 2.826 & 0.005 \\
& & 0.146 & 2.826 & 0.005
\end{tabular}

$R=0.284, F=27.628, p=0.000$.

Significant variables in univariate analysis were included, and multiple linear regression analysis was used to predict the related influential factors of gender equality awareness. Assumed predictors: gender, grade, gender satisfaction, attitudes toward boys' gender-neutral dressing, gender role. 
TABLE 5 | Multiple linear stepwise regression analysis of the study variables on gender equality awareness among boys and girls.

\begin{tabular}{|c|c|c|c|c|c|c|c|c|c|}
\hline \multirow[t]{2}{*}{ Dependent variable } & \multirow[t]{2}{*}{ Independent variables } & \multicolumn{4}{|c|}{ BOYS $^{1}$} & \multicolumn{4}{|c|}{ GIRLS $^{2}$} \\
\hline & & $B$ & Beta & $t$ & $p$ & $B$ & Beta & $t$ & $p$ \\
\hline \multirow[t]{8}{*}{ Gender equality awareness } & (Constant) & -4.218 & & -1.106 & 0.271 & 5.401 & & 1.352 & 0.179 \\
\hline & Attitudes toward boys' gender-neutral dressing & 2.123 & 0.212 & 2.591 & 0.011 & & & & \\
\hline & Gender satisfaction & 2.254 & 0.185 & 2.238 & 0.027 & & & & \\
\hline & grade & 1.684 & 0.335 & 4.001 & 0.000 & 2.428 & 0.493 & 6.624 & 0.000 \\
\hline & The only child & 3.014 & 0.167 & 2.071 & 0.041 & -2.892 & -0.146 & -1.998 & 0.048 \\
\hline & The left-behind children & & & & & 2.269 & 0.143 & 1.981 & 0.050 \\
\hline & Number of opposite-sex friends & & & & & 0.988 & 0.168 & 2.302 & 0.023 \\
\hline & Gender role & & & & & 1.223 & 0.179 & 2.431 & 0.016 \\
\hline
\end{tabular}

${ }^{1} R^{1}=0.262, F=10.118, p=0.000$.

${ }^{2} R^{2}=0.352, F=13.923, p=0.000$

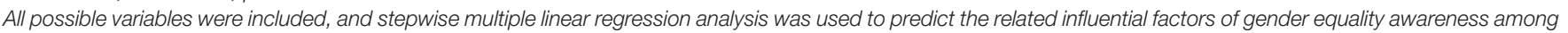

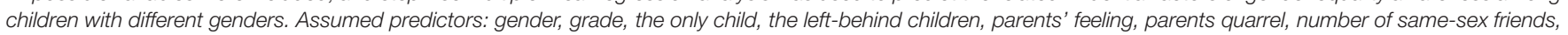
number of opposite-sex friends, gender satisfaction, attitudes toward boys' gender-neutral dressing, attitudes toward girls' gender-neutral dressing, gender role.

TABLE 6 | Multiple linear regression analysis of the study variables on self-esteem.

\begin{tabular}{|c|c|c|c|c|c|}
\hline Dependent variable & Independent variables & $B$ & Beta & $t$ & $p$ \\
\hline \multirow[t]{4}{*}{ Self-esteem } & (Constant) & 25.020 & & 19.284 & 0.000 \\
\hline & Gender role & 0.550 & 0.133 & 2.236 & 0.026 \\
\hline & Parents' feeling & -0.659 & -0.128 & -2.150 & 0.032 \\
\hline & Number of same-sex friends & 0.776 & 0.153 & 2.551 & 0.011 \\
\hline
\end{tabular}

$R=0.071, F=6.759, p=0.000$

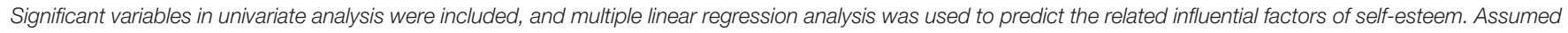
predictors: grade, parents' feeling, number of same-sex friends, gender role.

TABLE 7 | Multiple linear stepwise regression analysis of the study variables on self-esteem among boys and girls.

\begin{tabular}{|c|c|c|c|c|c|c|c|c|c|}
\hline \multirow[t]{2}{*}{ Dependent variable } & \multirow[t]{2}{*}{ Independent variables } & \multicolumn{4}{|c|}{ BOYS $^{1}$} & \multicolumn{3}{|c|}{ GIRLS $^{2}$} & \multirow[b]{2}{*}{$p$} \\
\hline & & $B$ & Beta & $t$ & $p$ & $B$ & Beta & $t$ & \\
\hline \multirow[t]{3}{*}{ Self-esteem } & (Constant) & 30.085 & & 32.611 & 0.000 & 25.596 & & 31.191 & 0.000 \\
\hline & Parents' feeling & -1.214 & -0.233 & -2.588 & 0.011 & & & & \\
\hline & Gender role & & & & & 0.967 & 0.328 & 2.946 & 0.004 \\
\hline
\end{tabular}

${ }^{1} R^{1}=0.054, F=6.695, p=0.011$.

${ }^{2} R^{2}=0.062, F=8.682, p=0.004$

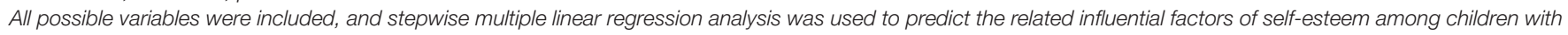

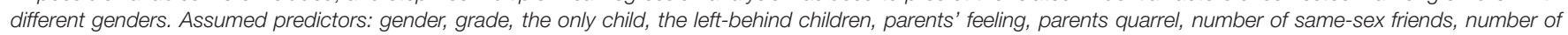
opposite-sex friends, gender satisfaction, attitudes toward boys' gender-neutral dressing, attitudes toward girls' gender-neutral dressing, gender role.

TABLE 8 | Multiple linear regression analysis of the study variables on subjective well-being.

\begin{tabular}{|c|c|c|c|c|c|}
\hline Dependent variable & Independent variables & $B$ & Beta & $t$ & $p$ \\
\hline \multirow[t]{2}{*}{ Subjective well-being } & (Constant) & 1.374 & & 5.757 & 0.000 \\
\hline & Parental quarrel & 0.590 & 0.251 & 4.255 & 0.000 \\
\hline
\end{tabular}

$R=0.063, F=18.107, p=0.000$.

Significant variables in univariate analysis were included, and multiple linear regression analysis was used to predict the related influential factors of subjective well-being.

Assumed predictors: parents' feeling, parental quarrel, number of same-sex friends.

children with more same-sex friends also had higher self-esteem, in line with the results of Wang (2013). The implication is that good peer relationships can promote self-esteem effectively. Therefore, while conducting gender education, schools and teachers should also help children become familiar with and communicate with more friends through group games and team tasks. These activities can help to promote children's self-esteem and mental health. In addition, we found that children with poor parental feelings had lower self-esteem, along with children whose parents often quarreled. This reflects the importance of parents and the family environment on children's mental health. Therefore, school teachers should also take advantage 
TABLE 9 | Multiple linear stepwise regression analysis of the study variables on subjective well-being among boys and girls.

\begin{tabular}{|c|c|c|c|c|c|c|c|c|c|}
\hline \multirow[t]{2}{*}{ Dependent variable } & \multirow[t]{2}{*}{ Independent variables } & \multicolumn{4}{|c|}{ BOYS } & \multicolumn{4}{|c|}{ GIRLS $^{2}$} \\
\hline & & $B$ & Beta & $t$ & $p$ & $B$ & Beta & $t$ & $p$ \\
\hline \multirow[t]{2}{*}{ Subjective well-being } & (Constant) & & & & & 1.258 & & 3.699 & 0.000 \\
\hline & Parental quarrel & & & & & 0.750 & 0.306 & 3.698 & 0.000 \\
\hline
\end{tabular}

$R^{2}=0.094, F=13.677, p=0.000$.

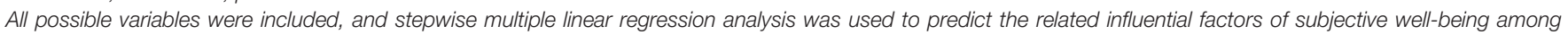

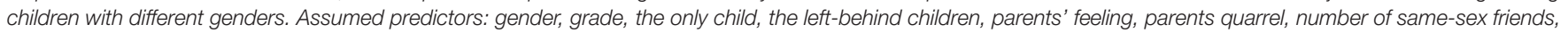
number of opposite-sex friends, gender satisfaction, attitudes toward boys' gender-neutral dressing, attitudes toward girls' gender-neutral dressing, gender role.

of opportunities, such as family visits and class meetings, to explain the psychological characteristics and needs of schoolage children to parents and other guardians, guiding them in building a positive family atmosphere that can improve children's self-esteem and subjective well-being.

Our analysis of the factors influencing self-esteem and subjective well-being among school-age children of different genders found that the self-esteem of girls is related mainly to gender roles and beneficial androgynous traits. This may relate to the positive effect of masculinity on children's selfesteem (Lo et al., 2019). School-age boys' self-esteem was affected mainly by their parental feelings. Boys with good parental feelings had higher self-esteem. Parental quarrels were more harmful to the subjective well-being of school-age girls; the more parents quarreled, the lower the subjective well-being of the girls. Therefore, when offering psychological guidance for children and communication with parents, schools and teachers should provide targeted education and guidance according to the influence of different gender roles and family conditions on the mental health of the boys and girls.

\section{LIMITATIONS}

First, we investigated only the effects of some general demographic data and gender roles on gender equality awareness, self-esteem, and subjective well-being among school-age children. We did not, therefore, study children's social support, internal psychological qualities, and more comprehensive demographic data. Second, we only surveyed children in two primary schools in the Hunan Province in China, which may cause sampling error. Third, our study has not sorted out a guiding theoretical framework. Future studies should expand the sample size to establish a more appropriate theoretical framework and test comprehensively the effects of internal and external factors on gender equality awareness, self-esteem, and the subjective well-being of school-age children.

\section{CONCLUSION}

We investigated and analyzed the environmental situations and factors influencing gender equality awareness, self-esteem, and subjective well-being among school-age children of different genders. We found that gender equality awareness among schoolage children in all areas was significantly correlated. Both boys and girls had the lowest scores for gender equality in occupational fields. Additionally, the factors that influence gender equality awareness, self-esteem, and subjective well-being among boys and girls differed. However, androgynous traits contributed to gender equality awareness and also self-esteem development in both boys and girls. In sum, schools and teachers should strengthen gender equality awareness of occupational fields and provide gender education and psychological counseling for each child. Specifically, schools and teachers should conduct intersex education to help children to develop strong androgynous temperaments to promote children's gender equality awareness and self-esteem development.

\section{DATA AVAILABILITY STATEMENT}

The raw data supporting the conclusions of this article will be made available by the authors, without undue reservation.

\section{ETHICS STATEMENT}

The studies involving human participants were reviewed and approved by the Xiangya School of Nursing, Central South University (Ethical Grant Number: E201947). Written informed consent to participate in the study was provided by the participants' legal guardian/next of kin.

\section{AUTHOR CONTRIBUTIONS}

YL and MZ designed the study, collected the data, analyzed the data, interpreted the results, and wrote the manuscript. JZ conducted the statistical analysis and provided consultation in the study design and intervention development process. YC and YT interpreted the data, prepared the manuscript, and revised the manuscript. BY and YP conducted the statistical analysis and interpreted the result. JPZ designed the study, analyzed the data, interpreted the results, and provided consultation in the study design and intervention development process. All authors have read and reviewed the final manuscript.

\section{ACKNOWLEDGMENTS}

The authors thank all the participants and researchers who were involved in this study. 


\section{REFERENCES}

Arcand, M., Juster, R. P., Lupien, S. J., and Marin, M. F. (2020). Gender roles in relation to symptoms of anxiety and depression among students and workers. Anxiety Stress coping 33, 661-674. doi: 10.1080/10615806.2020.1774560

Atkins, M. S., Cappella, E., Shernoff, E. S., Mehta, T. G., and Gustafson, E. L. (2017). Schooling and children's mental health: realigning resources to reduce disparities and advance public health. Annu. Rev. Clin. Psychol. 13, 123-147. doi: 10.1146/annurev-clinpsy-032816-045234

Bates, L. M., Hankivsky, O., and Springer, K. W. (2009). Gender and health inequities: a comment on the final report of the WHO commission on the social determinants of health. Soc. Sci. Med. (1982) 69, 1002-1004. doi: 10.1016/ j.socscimed.2009.07.021

Bem, S. L. (1974). The measurement of psychological androgyny. J. Consult. Clin. Psychol. 42, 155-162. doi: 10.1037/h0036215

Bem, S. L. (1981). Gender schema theory: a cognitive account of sex typing. Psychol. Rev. 88, 354-364. doi: 10.1037/0033-295x.88.4.354

Brener, N., and Demissie, Z. (2018). Counseling, psychological, and social services staffing: policies in U.S. School Districts. Am. J. Prevent. Med. 54(6 Suppl 3), S215-S219. doi: 10.1016/j.amepre.2018.01.031

Brody, L. R. (1999). Gender, Emotion, and the Family. Cambridge, MA: Harvard University Press.

Campbell, O., Bann, D., and Patalay, P. (2021). The gender gap in adolescent mental health: a cross-national investigation of 566,829 adolescents across 73 countries. SSM Popul. Health 13:100742. doi: 10.1016/j.ssmph.2021.100742

Casas, F., and González-Carrasco, M. (2019). Subjective well-being decreasing with age: new research on children over 8. Child Dev. 90, 375-394. doi: 10.1111/cdev. 13133

Chaplin, T. M., and Aldao, A. (2013). Gender differences in emotion expression in children: a meta-analytic review. Psychol. Bull. 139, 735-765. doi: 10.1037/ a0030737

Chen, X. X. (2016). A Comparative Study on the Understanding of Gender Roles Between High and Low Grade Primary School Students. Nanjing: Nanjing Normal University.

Chu, P. S., Saucier, D. A., and Hafner, E. (2010). Meta-analysis of the relationships between social support and well-being in children and adolescents. J. Soc. Clin. Psychol. 29, 624-645. doi: 10.1521/jscp.2010.29.6.624

Clarke, A., Friede, T., Putz, R., Ashdown, J., Martin, S., Blake, A., et al. (2011). Warwick-Edinburgh Mental Well-Being Scale (WEMWBS): validated for teenage school students in England and Scotland. A mixed methods assessment. BMC Public Health 11:487. doi: 10.1186/1471-2458-11-487

Cui, Y. (2013). Pediatric Nursing. Beijing: People's Medical Publishing House, 4.

Derdikman-Eiron, R., Indredavik, M. S., Bratberg, G. H., Taraldsen, G., Bakken, I. J., and Colton, M. (2011). Gender differences in subjective well-being, selfesteem and psychosocial functioning in adolescents with symptoms of anxiety and depression: findings from the Nord-Trøndelag Health Study. Scand. J. Psychol. 52, 261-267. doi: 10.1111/j.1467-9450.2010.00859.x

Fang, G. (2010). Psychology of Gender. Anhui: Anhui Education Press.

Feingold, A. (1994). Gender differences in personality: a meta-analysis. Psychol. Bull. 116, 429-456. doi: 10.1037/0033-2909.116.3.429

Gadoth, A., and Heymann, J. (2020). Gender parity at scale: examining correlations of country-level female participation in education and work with measures of men's and women's survival. EClinicalMedicine 20:100299. doi: 10.1016/j. eclinm.2020.100299

Happell, B., Wilson, K., Platania-Phung, C., and Stanton, R. (2017). Physical health and mental illness: listening to the voice of carers. J. Ment. Health (Abingdon, England) 26, 127-133. doi: 10.3109/09638237.2016.1167854

Holter, ØG. (2014). What's in it for Men? Men Masc. 17:5. doi: 10.1177/ $1097184 X 14558237$

Jiang, Q., Li, Y., and Sanchez-Barricarte, J. J. (2016). Fertility intention, son preference, and second childbirth: survey findings from Shaanxi Province of China. Soc. Indic. Res. 125, 935-953. doi: 10.1007/s11205-015$0875-\mathrm{z}$

Jin, F. (2014). Research on Education Promotion of Sound Personality Development in Preschool Children Aged 3-6 Years. Dalian: Liaoning Normal University.

Joshanloo, M., and Daemi, F. (2015). Self-esteem mediates the relationship between spirituality and subjective well-being in Iran. Int. J. Psychol. 50, 115-120. doi: 10.1002/ijop.12061
Juster, R. P., Pruessner, J. C., Desrochers, A. B., Bourdon, O., Durand, N., Wan, N., et al. (2016). Sex and gender roles in relation to mental health and allostatic load. Psychosom. Med. 78, 788-804. doi: 10.1097/PSY.0000000000000351

Kolip, P., and Lange, C. (2018). Gender inequality and the gender gap in life expectancy in the European Union. Eur. J. Public Health 28, 869-872. doi: 10.1093/eurpub/cky076

Kolip, P., Lange, C., and Finne, E. (2019). Gleichstellung der geschlechter und geschlechterunterschiede in der lebenserwartung in Deutschland [Gender equality and the gender gap in life expectancy in Germany]. Bundesgesundheitsblatt Gesundheitsforschung Gesundheitsschutz 62, 943-951. doi: 10.1007/s00103-019-02974-2

Lee, D. J. (1969). Society and the adolescent self-image. Sociology 3, 280-280. doi: $10.1177 / 003803856900300250$

Li, E. (2016). International Comparative Study of Occupational Gender Segregation. Shenyang: Shenyang Normal University.

$\mathrm{Li}, \mathrm{X}$. (2019). Study on the Promotion of Children's Gender Role Cognition Through Androgynous Education-Analysis of Social Work Service Based on the "Become Better self" Growth Group. Wuhan: Huazhong University of Science and Technology.

Li, Z. Y. (2007). An Approach to the Model of Children's Psychological Guidance: The Theory and Practice of Penetration, Self-growth Model. Shanghai: East China Normal University.

Liao, G. Y., and Lian, R. (2020). Differences of mental health changes between only and Non--only children: a cross-temporal meta-analysis. J. Southw. Univ. (Soc. Sci. Edn.) 46, 117-126. doi: 10.13718/j.cnki.xdsk.2020.03.013

Liao, L. P., and Zhang, C. L. (2020). Does "son preference" harm girls' health? Econ. Rev. 02, 139-154. doi: 10.19361/j.er.2020.02.09

Liu, Y. B. (2015). Researches on Gender Equality Education in Taiwan and Its Enlightenment. Changchun: Changchun Normal University.

Lo, I., Kim, Y. K., Small, E., and Chan, C. (2019). The gendered self of chinese lesbians: self-esteem as a mediator between gender roles and depression. Arch. Sex. Behav. 48, 1543-1554. doi: 10.1007/s10508-019$1402-0$

Loo, K. K., Luo, X., Su, H., Presson, A., and Li, Y. (2009). Dreams of tigers and flowers: child gender predictions and preference in an urban mainland Chinese sample during pregnancy. Women Health 49, 50-65. doi: 10.1080/ 03630240802694673

Looze, M. E., Huijts, T., Stevens, G., Torsheim, T., and Vollebergh, W. (2018). The happiest kids on earth. Gender equality and adolescent life satisfaction in Europe and North America. J. Youth Adolesc. 47, 1073-1085. doi: 10.1007/ s10964-017-0756-7

Lorish, C. D., and Maisiak, R. (1986). The face scale: a brief, nonverbal method for assessing patient mood. Arthr. Rheum. 29, 906-909. doi: 10.1002/art. 1780290714

Lu, Q., and Su, Y. J. (2003). Revision of bem sex role inventory. Chin. Ment. Health J. 546, 550-553.

Nartova-Bochaver, S., Donat, M., and Rüprich, C. (2019). Subjective well-being from a just-world perspective: a multi-dimensional approach in a student sample. Front. Psychol. 10:1739. doi: 10.3389/fpsyg.2019.01739

Okenwa-Emgwa, L., and von Strauss, E. (2018). Higher education as a platform for capacity building to address violence against women and promote gender equality: the Swedish example. Public Health Rev. 39:31. doi: 10.1186/s40985018-0108-5

Polderman, T., Kreukels, B., Irwig, M. S., Beach, L., Chan, Y. M., Derks, E. M., et al. (2018). The biological contributions to gender identity and gender diversity: bringing data to the table. Behav. Genet. 48, 95-108. doi: 10.1007/s10519-0189889-z

Rose, A. J., and Rudolph, K. D. (2006). A review of sex differences in peer relationship processes: potential trade-offs for the emotional and behavioral development of girls and boys. Psychol. Bull. 132, 98-131. doi: 10.1037/00332909.132.1.98

Rutter, M., Kim-Cohen, J., and Maughan, B. (2006). Continuities and discontinuities in psychopathology between childhood and adult life. J. Child Psychol. Psychiatry 47, 276-295. doi: 10.1111/j.1469-7610.2006. 01614.x

Savoye, I., Moreau, N., Brault, M. C., Levêque, A., and Godin, I. (2015). Well-being, gender, and psychological health in school-aged children. Arch. Public Health 73:52. doi: 10.1186/s13690-015-0104-x 
Schmitt, D. P., Long, A. E., McPhearson, A., O’Brien, K., Remmert, B., and Shah, S. H. (2017). Personality and gender differences in global perspective. Int. J. Psychol. 52(Suppl. 1), 45-56. doi: 10.1002/ijop. 12265

Solbes-Canales, I., Valverde-Montesino, S., and Herranz-Hernández, P. (2020). Socialization of gender stereotypes related to attributes and professions among young Spanish school-aged children. Front. Psychol. 11:609. doi: 10.3389/fpsyg. 2020.00609

Sun, Y. M. (2010). Occupational Gender Stereotypes and Their Intervention. Suzhou: Soochow University.

Syed, S. (2017). Introducing gender equity to adolescent school children: a mixed methods' study. J. Fam. Med. Primary Care 6, 254-258. doi: 10.4103/2249-4863. 220020

Tang, W. W., Gai, X. S., and Zhao, Y. (2011). Gender differences in primary school students' sociality adaptation. J. Inner Mongolia Norm. Univ. (Philos. Soc. Sci. Edn.) 40, 139-144.

Tennant, R., Hiller, L., Fishwick, R., Platt, S., Joseph, S., Weich, S., et al. (2007). The Warwick-Edinburgh Mental Well-being Scale (WEMWBS): development and UK validation. Health Qual. Life Outc. 5:63. doi: 10.1186/1477-75 25-5-63

Trautner, H. M., Ruble, D. N., Cyphers, L., Kirsten, B., Behrendt, R., and Hartmann, P. (2005). Rigidity and flexibility of gender stereotypes in children: developmental or differential? Infant Child Dev. 14, 365-381. doi: 10.1002/ icd.399

Wang, K. J. (2013). A Study on the Development Characteristics and Influencing Factors of Middle School Students' Subjective Well-Being. Xi An: Shaanxi Normal University.

Wang, M. Q. (2021). The Relationship Between Gratitude and Subjective WellBeing in Primary School Students: The Mediating Role of Mental Health. Tianjin: Tianjin Normal University.

Wang, X. Y. (2015). Investigation on the status quo of self-consciousness of leftbehind children and analysis of influencing factors. J. Jilin Med. Coll. 36, 33-34. doi: 10.13845/j.cnki.issn1673-2995.2015.01.015

Wang, X., Nie, W., and Liu, P. (2020). Son preference and the reproductive behavior of rural-urban migrant women of childbearing age in China: empirical evidence from a cross-sectional data. Int. J. Environ. Res. Public Health 17:3221. doi: 10.3390/ijerph17093221

Weber, S., Puskar, K. R., and Ren, D. (2010). Relationships between depressive symptoms and perceived social support, self-esteem, \& optimism in a sample of rural adolescents. Issues Mental Health Nurs. 31, 584-588. doi: 10.3109/ 01612841003775061

Wood, W., and Eagly, A. H. (2002). A cross-cultural analysis of the behavior of women and men: implications for the origins of sex differences. Psychol. Bull. 128, 699-727. doi: 10.1037/0033-2909.128.5.699

Yu, X., and Ji, F. Y. (1993). The self-esteem scale, SES. Chin. Ment. Health J. 251-252.

Zaninotto, P., and Steptoe, A. (2019). Association between subjective well-being and living longer without disability or illness. JAMA Netw. Open 2:e196870. doi: 10.1001/jamanetworkopen.2019.6870

Zhang, A. F. (2012). Primary School Students' Subjective Well-Being, and its Relations with Personality and Parenting Style. Jinan: Shandong Normal University.

Zhang, L. H. (2004). The Study on the Structure \& Developmental Characteristics and Influencing Factors of Children's Self-Esteem Aged 3 to 9. Dalian: Liaoning Normal University.

Zhang, Z. J. (2010). Behavioral medical instrument manual. Chin. J. Behav. Med. Sci. 10:110.

Zhou, Y., and Liu, X. P. (2011). Character strengths of college students: the relationship between character strengths and subjective well-being. Psychol. Dev. Educ. 27, 536-542. doi: 10.16187/j.cnki.issn1001-4918.2011.05.005

Conflict of Interest: The authors declare that the research was conducted in the absence of any commercial or financial relationships that could be construed as a potential conflict of interest.

Publisher's Note: All claims expressed in this article are solely those of the authors and do not necessarily represent those of their affiliated organizations, or those of the publisher, the editors and the reviewers. Any product that may be evaluated in this article, or claim that may be made by its manufacturer, is not guaranteed or endorsed by the publisher.

Copyright (c) 2022 Li, Zuo, Peng, Zhang, Chen, Tao, Ye and Zhang. This is an open-access article distributed under the terms of the Creative Commons Attribution License (CC BY). The use, distribution or reproduction in other forums is permitted, provided the original author(s) and the copyright owner(s) are credited and that the original publication in this journal is cited, in accordance with accepted academic practice. No use, distribution or reproduction is permitted which does not comply with these terms. 